\title{
CAN THE SPECIES RICHNESS OF SPIDERS BE DETERMINED?
}

\author{
BY ROBERT L. EDWARDS \\ Research Associate, USNM \\ Box 505, Woods Hole, MA 02543
}

\begin{abstract}
The jackknife estimate of species richness for spiders in a study area on southwest Cape Cod was 373.1 species, with a confidence interval of 28.2 species. Over a period of six years 390 species had been recorded in that area. Fourteen habitats were sampled using conventional sampling techniques. The sample data for each habitat was examined for various aspects of comparability. It is suggested that for the purposes of calculating the jackknife estimate of species richness, a minimum number of individuals be collected from each habitat.
\end{abstract}

\section{INTRODUCTION}

Following the development of the species diversity concept by Fisher et al. (1943), the subject has received a great deal of attention by biostatisticians and ecologists. Recently attention has shifted from counting the number of individuals and species in a sample on the assumption that populations were being adequately sampled. Populations are seldom, if ever, uniformly distributed. It is now appreciated that one is usually sampling area, not populations directly (Kempton, 1979; Smith and Grassle, 1977).

Cape Cod is richly endowed with spiders. After six years of collecting, the number of species I have recorded in Falmouth township, Barnstable County, is 468. Additional species are still showing up (Edwards, 1993). One hundred fifty-eight species were reported associated with rural delivery mail boxes in the nearby township of Mashpee (Edwards et al., 1991); seven of these species have not yet been taken in Falmouth. Martha's Vineyard, an island barely four kilometers south of Falmouth, also has several species that have not been collected in Falmouth (Thomas

Manuscript received 29 April 1993. 
Chase, pers. comm.). The large number of species found in the area of Falmouth township (circa 250 square kilometers) is comparable to what one might expect to find in warmer tropical regions. Such species richness provides a useful test area in which to examine certain aspects related to the complex task of estimating species diversity.

Heltshe and Forrester (1983) produced a nonparametric jackknife estimator for species richness based on quadrat sampling. Computer simulation techniques were used to study the performance of the jackknife procedure for different quadrat sizes and total area sampled as well as the number of samples (quadrats), coupled with simulated high and low skew populations. Although the confidence interval coverage for highly skewed populations can be very poor and the jackknife underestimates species when the number of rare species is large, it does offer a new and potentially useful approach to the estimation of species richness. The results of such simulations are not directly transferable to the field but do provide some general guidance.

This paper briefly explores the variability and species diversity of samples obtained in two study areas. It has the particular goal of estimating the total number of species in one of the study areas (FCWMA). The utility of the jackknife estimator of species richness, J(ESR), of Heltshe and Forrester (1983) is given particular attention.

\section{DESCRIPTION OF THE STUDY AREAS}

Spiders were collected in two localities, both in Falmouth township, Barnstable County, Cape Cod, Massachusetts. One locality in East Falmouth was chosen for an extended examination on one habitat. A second locality, the Frances Crane Wildlife Management Area (FCWMA), was chosen to estimate the number of species in an area with a wide array of habitats.

\section{East Falmouth}

Sampling was limited to leaf litter of a mixed oak-pine second growth woods ( 20 hectare). The needle-deciduous leaf litter averaged ca. $10 \mathrm{~cm}$ in depth, and had a thin layer of decomposed material at the bottom next to sandy soil. The understory was a spotty mixture of small shrubs $( \pm 1 \mathrm{~m})$, largely ericaceous heaths. Elevation $15 \mathrm{~m}$, climate as detailed in paragraph below. 


\section{Frances Crane Wildlife Management Area}

This location was chosen for the principal part of the study. The entire 1,255 hectare (ha) area was once farmed. At present it is maintained for multiple recreational purposes. Much of the area is now an older second growth forest about 50 years old. With the exception of one small pond, there are no streams or other bodies of water. The topography is relatively flat; average elevation varies from 20 to 30 meters above sea level. The soils are sandy loams. Annual rainfall ranges from 16 to $20 \mathrm{~cm}$. The annual temperature varies from $-2^{\circ}$ to $21^{\circ} \mathrm{C}$. Because of the area's proximity to the ocean, spring is relative cool and autumn warm.

The principal vegetation and percent total area of FCWMA include: 1) a second growth scarlet and white oak forest (Quercus coccinea and $Q$. alba) with a well defined, dense understory of waist high ericaceous heaths, dominated by Gaylussacia (ca. 35\%); 2) fields dominated by forbs, some with scattered red cedars (Juniperus virginiana) and other introduced and invasive species, (ca. 25\%), some of which are periodically cut over or plowed and planted to support various game birds and animals; 3 ) less defined regions of coniferous woodland dominated by pitch pine (Pinus rigida), and with a substantial $2 \mathrm{~m}$ high understory of scrub oak (Quercus ilicifolia) and other large woody shrubs (ca. 15\%); and 4) fields dominated by grasses, some maintained as such by mowing (ca. 5\%). The remainder of the area includes a small pond and its immediate surroundings, power line clearings, roads, paths, and parking lots. There is a great deal of clearly defined 'edge' between each of these components. Within a few kilometers of the FCWMA, there are decidedly different habitats, including those bordering the ocean shore and brackish estuaries. These have different assemblages of spiders, and are not included in this study.

\section{Materials AND MethodS}

\section{East Falmouth}

Eighty quadrats (each $0.25 \mathrm{~m}^{2}$ ) of mixed coniferous-deciduous forest litter (M82L) were sampled. Generally, the underlying consolidated duff was excluded. Collections were made at weekly intervals, weather permitting, in January and February, 1990, when the duff would normally be frozen. However, following a record cold December (ca. $7^{\circ} \mathrm{C}$ below normal), January and February 
were unexpectedly warm $\left(4^{\circ}\right.$ to $5^{\circ} \mathrm{C}$ above normal). Consequently some of the samples included small portions of thawed, underlying duff.

\section{Frances Crane Wildlife Management Area}

Collecting in the FCWMA took place from the middle of June through September of both 1989 and 1991. This period was chosen to maximize the probability of collecting mature individuals. Some spider species were immature throughout this period and were difficult or impossible to identify to species.

Fourteen well defined habitats were chosen. Based on the author's collecting experience, these habitats supported different species assemblages, differed in their physical structure, and were large enough to sustain extensive sampling. The data base codes for each habitat (below in parentheses) are used in some of the figures and graphs.

There was no single sampling technique that could be used for each different habitat. The techniques chosen represented the author's best judgment for selecting the method that provided the greatest probability of taking all species present. Each of the habitats was sampled periodically, but not on a strictly random or systematic basis. Each sampling sequence took place in non-overlapping areas of each chosen habitat. For example, 4 pitfall traps were placed randomly, separated by more than $15 \mathrm{~m}$, in a particular habitat for two cycles of five days, and then moved to the same habitat in a different part of the overall area. Only the grass habitat was too small to avoid some overlap in sampled area.

1. Red cedar foliage (C43S): The cedars sampled included scattered trees and small clumps of trees in open fields. Samples were obtained by beating the lower crown foliage. A rectangular plastic pan (surface area of $0.083 \mathrm{~m}^{2}$ ) was held under branches that completely 'shadowed' the pan. The foliage was then struck sharply with a wooden paddle $(7.5 \mathrm{~cm} \times 45 \mathrm{~cm})$, until no more spiders fell. Each quadrat consisted of 12 repetitions of this procedure and represented an area of ca. $1 \mathrm{~m}^{2}$ of foliage.

2. Pitch pine foliage (C40S): The same sampling procedure was used, i.e., beating foliage (see 1 above).

3. Pine understory (C73S): The pine understory is typically made up of large shrubs dominated by scrub oak (Quercus ilicifolia), and averaged $2 \mathrm{~m}$ in height. Because this shrubbery was too difficult to sweep, it was sampled by beating (see 1 above). 
4. Deciduous understory (D73S): Heaths comprised the understory of the second growth oak woods, and were swept with a 36 $\mathrm{cm}$ diameter canvas sweep net. A set of 50 non-overlapping sweeps of upper plant portions constituted a quadrat. The heaths varied in their coverage of the forest floor from site to site. A set of 50 sweeps was estimated to have sampled a volume of ca. $5 \mathrm{~m}^{3}$.

5. Pitch pine litter $(\mathrm{C} 81 \mathrm{~L})$ : Litter in the pine woods was dominated by pine needles, sometimes exclusively, but occasionally with an admixture of leaves from deciduous plants. It varied in depth from 3.5 to $6 \mathrm{~cm}$ with a thin layer $( \pm 2 \mathrm{~cm})$ of decomposed needles at the bottom. Each quadrat was $0.25 \mathrm{~m}^{2}$ and included material down to the consolidated duff. The collected material was placed in cloth bags for transport to the laboratory, where spiders were sorted out by hand, usually within 24 hours, but always within 48 hours.

6. Deciduous litter (D80L): Sampled as in the case of pine litter (see 5 above). Deciduous leaf litter varied in depth from 4 to $8 \mathrm{~cm}$, and only occasionally had a thin layer of consolidated duff beneath. Typically there was a year-round cover of undecayed oak leaves.

7. Pitch pine forest floor (C81P): Pitfall traps were similar to those described by Houseweart et al. (1979). The funnel had a rim diameter of $20 \mathrm{~cm}$ (surface area $=314 \mathrm{~cm}^{2}$ ), and an elevated cover (ca. $10 \mathrm{~cm}$ ) provided some protection from rain. The traps were examined every five days, weather permitting. Each five-day collection period was defined as a quadrat. Denatured ethanol was used in the trap for preservation. During the study there were several extended periods of heavy rain, occasionally flooding the collecting jar and spoiling the sample. Only those samples taken during periods with no significant rain were used. The traps were frequently upset by animals, including humans, thus rendering the sampling procedure both time consuming and frustrating.

8. Deciduous forest floor (D80P): Pitfall traps and procedure same as in pine woods floor (see 7 above).

9. Old field ground surface (F31P): Sampled with pitfall traps; procedure same as in pine woods (see 7 above). These old fields were dominated by forbs, typically Compositae and Umbelliferae, and had minimal litter at ground level. Some fields were being invaded by cedars, pitch pine, and Russian olive (introduced). 
10. Grass field ground surface (F30P): Pitfall traps and collection procedures same as in pine woods (see 7 above). The grass dominated fields were of two types: successional grasses with interspersed patches of reindeer lichen which dominated the surfaces of old gravel and sand borrow pits, and areas maintained as grass by seasonal mowing.

11. Grass field foliage (F30S): Fields dominated by grasses $(35-70 \mathrm{~cm}$ in height), were swept with a $36 \mathrm{~cm}$ canvas sweep net. Each quadrat consisted of 50 non-overlapping sweeps. Areas with widely separated grassy clumps and those regularly mowed were avoided.

12. Old field foliage (F31S): Same procedure as in grass fields (see 11 above). Forbs dominated these fields and all were densely vegetated. The plants varied in height $(0.3$ to $1.5 \mathrm{~m})$.

13. Oak tree trunks (D47T): Only white oaks were sampled. The trunks of white oaks are usually smooth with scattered patches of moss and lichen. Two methods of collecting were used simultaneously. First, a 15 by $45 \mathrm{~cm}$ band of burlap, folded over lengthwise and with the open side down, was stapled to each tree trunk sampled ca. $1 \mathrm{~m}$ above the ground. This procedure was used to attract spiders that inhabit the deep hollows and crevices of tree trunks. Second, a $0.2 \mathrm{~m}^{2}$ area of each sampled trunk was swept with a broad $(15 \mathrm{~cm})$, relatively stiff whitewash brush. Sampled trunk areas were 1.5 to $2.5 \mathrm{~m}$ above ground. A plastic pan was held underneath to catch the spiders as they were dislodged. Each quadrat consisted of five burlap strips and five trunk sweepings.

14. Pitch pine trunks (C40T): Pitch pines have scaly, rough, thick, and easily removed outer bark. A quadrat consisted of $1 \mathrm{~m}^{2}$ of outer bark (pried and scraped off with a trowel) taken from 3 to 5 trees in close proximity. The collected bark was broken up to expose and collect any spiders. Bark removal was followed by a careful examination of the trunk surface. This procedure was not feasible for smooth-barked pines (e.g., white pine).

All active collecting (e.g., sweeping and beating) was carried out in the afternoon. Specimens were preserved in $75 \%$ denatured ethyl alcohol. Each individual was identified to species if possible; otherwise, to genus. Specimens that could not be identified to species were saved until all material had been studied. Each individual was then carefully compared and identified as being the same or a different species. In most cases where individuals could 
not be identified as a particular species, such specimens occurred in more than one quadrat, and were not counted as unique. Aggregations of the earliest instars-e.g., lycosid spiderlings taken with a female; aggregations of recently hatched, but not yet dispersed spiderlings-were excluded from the counts.

The jackknife species diversity equation developed by Heltshe and Forrester (1983) was used for this study. The equation is:

$$
J(E S R)=s+\left(\frac{n-1}{n}\right) k
$$

where, $\mathrm{J}(\mathrm{ESR})=$ Jackknife estimate of species richness, $\mathrm{s}=$ total number of species observed in all quadrats, $\mathrm{n}=$ number of quadrats sampled, and $\mathrm{k}=$ number of unique species.

The equation for calculating variance is:

$$
\operatorname{varJ}(E S R)=\left(\frac{n-1}{n}\right)\left[\sum_{j=1}^{s}\left(j^{2} f_{j}\right)-\frac{k^{2}}{n}\right]
$$

where, $\operatorname{varJ}(E S R)=$ variance of jackknife estimate of species richness, $\mathrm{j}=$ number of quadrats with $\mathrm{f}$ unique species, and $\mathrm{f}=$ number of unique species in a quadrat.

The confidence limits for $\mathrm{J}(\mathrm{ESR})$ are obtained by:

$$
J(E S R) \pm t_{\alpha} \sqrt{\operatorname{var}}(J(E S R))
$$

where, $\mathrm{t}=$ Student's $\mathrm{t}$ value for $\mathrm{n}-1$ degrees of freedom .

The term 'unique' is defined as a species that occurs in only one quadrat, regardless of how many individuals may be involved. The $\mathrm{J}(\mathrm{ESR})$ equation cannot provide an estimate in excess of twice the number of species in a sample. Further, note that the sum of the number of species plus the number of species that are unique closely approximates the estimate of species richness. The failure to include a non-unique species decreases the J(ESR) by 1 (approximately); adding a species incorrectly increases J(ESR) by +1 (approximately). The error in J(ESR) when a unique species is incorrectly included is +2 (approximately) since this increases both the observed number of species and number of uniques. In the case 
of spiders the greatest source of error would probably lie in failing to recognize an immature as a unique species.

\section{RESUlTS AND Discussion}

\section{East Falmouth samples}

Eighty litter quadrats (each $0.25 \mathrm{~m}^{2}$ ) were collected in sets of 10 at weekly intervals during January and February, 1990. In all, 2161 specimens were taken, representing 98 species and 71 genera. The purpose of this collection was to examine the behavior of the parameters of the jackknife estimator with a large number of samples from a single, well defined habitat. The winter period was chosen to reduce bias created by active movements of spiders from area to area.

Jackknife estimates of numbers of species for each succeeding set of ten quadrats are provided in Fig. 1 and Table 1A. The J(ESR) ranged from 48.7 to 67.5 species, with considerable variation in estimates and variances among sets. For all 80 quadrats,

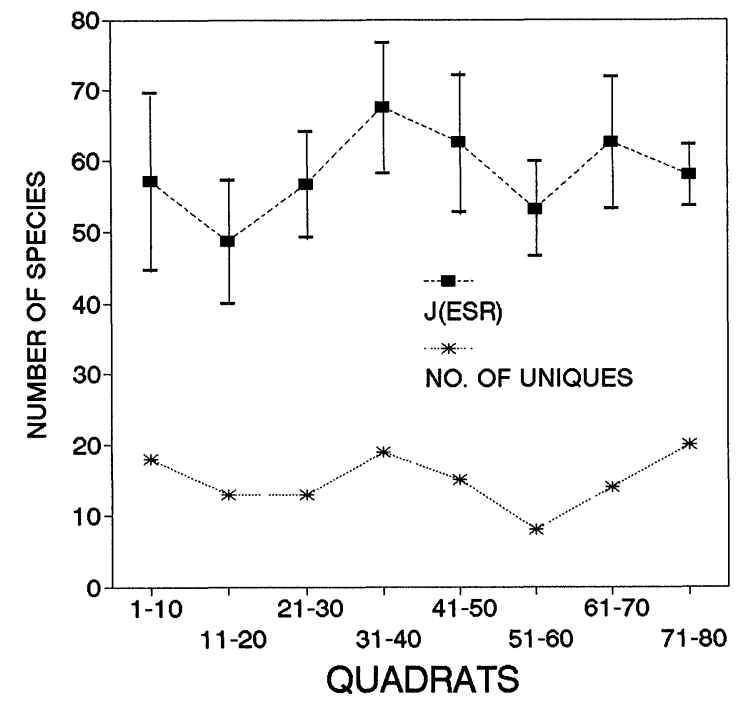

Figure 1. Species richness estimates, J(ESR), and number of unique species for each successive set of 10 samples. Bars indicate confidence interval limits. Litter samples from a mixed pine-oak forest, East Falmouth, January-February, 1990. 


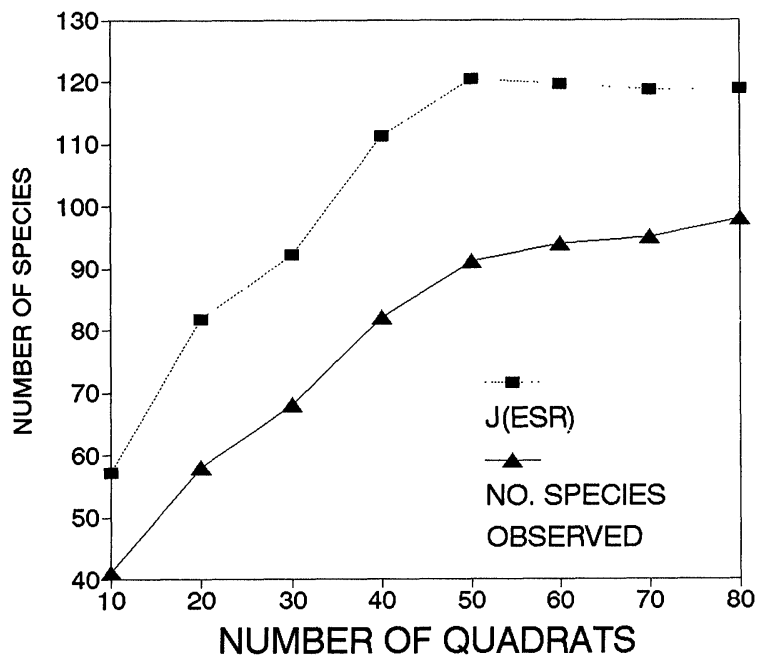

Figure 2. Species richness estimates, J(ESR), and species-effort curve for East Falmouth quadrats, accumulated by 10 's. Litter samples from a mixed pine-oak forest, East Falmouth, January-February, 1990.

$\mathrm{J}(\mathrm{ESR})$ is 122.7 species, with a variance of 18.9 and a confidence interval of 8.7 (Table 1B).

$\mathrm{J}(\mathrm{ESR})$ leveled off after 50 quadrats at about 120 species (Fig. 2). This suggests that 50 quadrats provided an adequate sample for this particular habitat. However, the number of species (specieseffort curve) was still slowly increasing after 80 quadrats.

\section{FCWMA samples}

Over 12,000 individuals, representing 147 genera and 304 species, were collected. Percentage representation by number of individuals of the twelve most abundant families of spiders in each habitat detailed above are shown in Fig. 3. The spider assemblages may be divided into three main groups: 1) those on vegetation above ground (first six habitats); 2) those inhabiting vertical surfaces, in FCWMA tree trunks (last two habitats); and 3) those living on or in material on the ground (middle six habitats). Erigonine spiders, particularly one species of the genus Ceraticelus, tend to dominate in the foliage of trees and understory shrubbery, with salticids and orb weavers also well represented. The two field habitats, grass and old field, are a distinctive subgroup of this first 


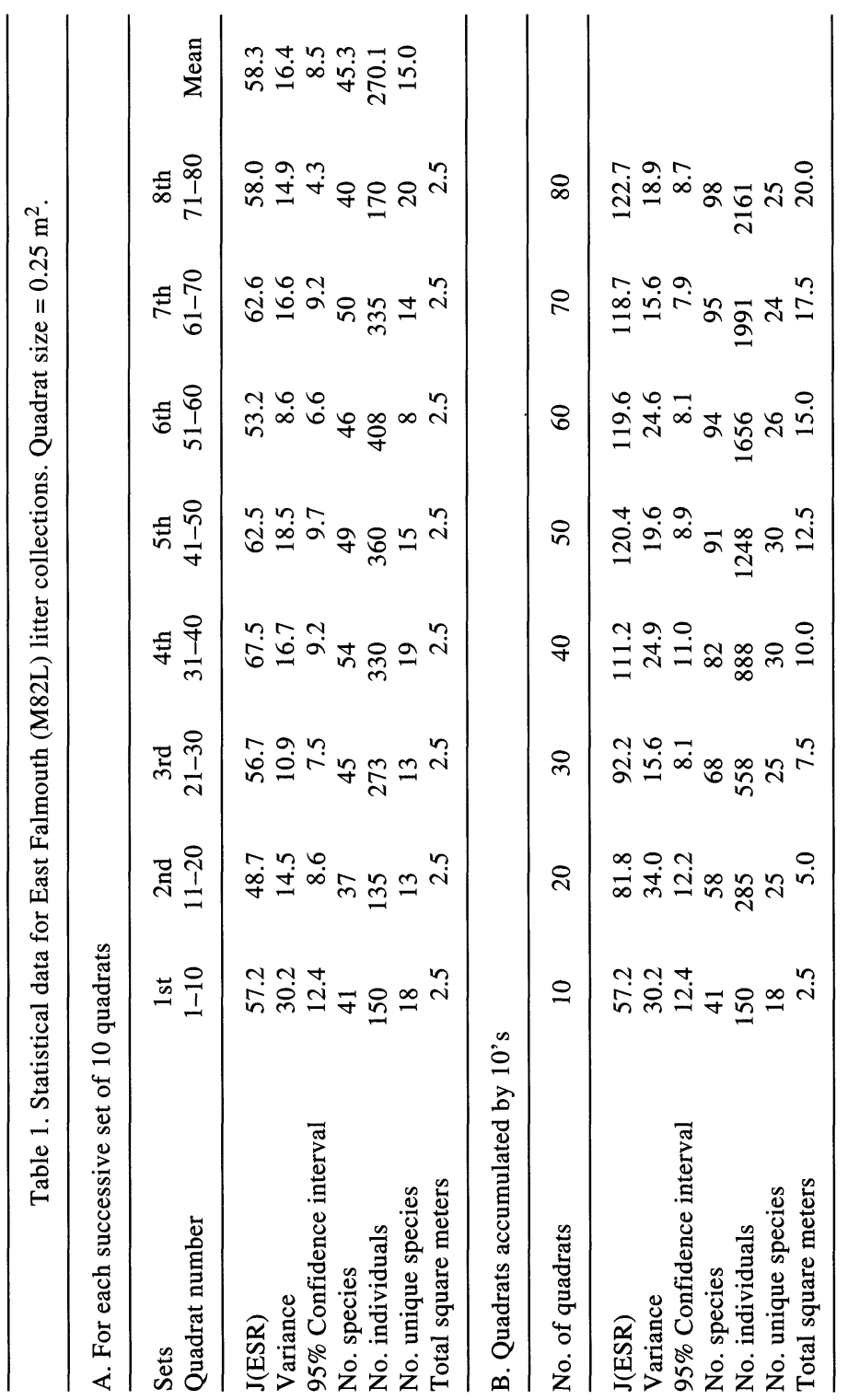


group, with relatively greater numbers of orb weavers (several genera and species). Both tree trunk habitats were dominated by relatively large numbers of comb-footed spiders, genera Theridion, Euryopis and Dipoena. The trunks of pitch pine (C40T) harbor large numbers of one philodromid species, Philodromus validus (Gertsch) and a thomisid spider species, Coriarachne versicolor Keyserling. The latter two species were seldom found on oak trunks (D47T). Wolf spiders (several genera and many species) characterized the surface habitats, especially those of fields (F31P, F30P). Litter habitats (D80L, C81L) were dominated by several erigonine genera.

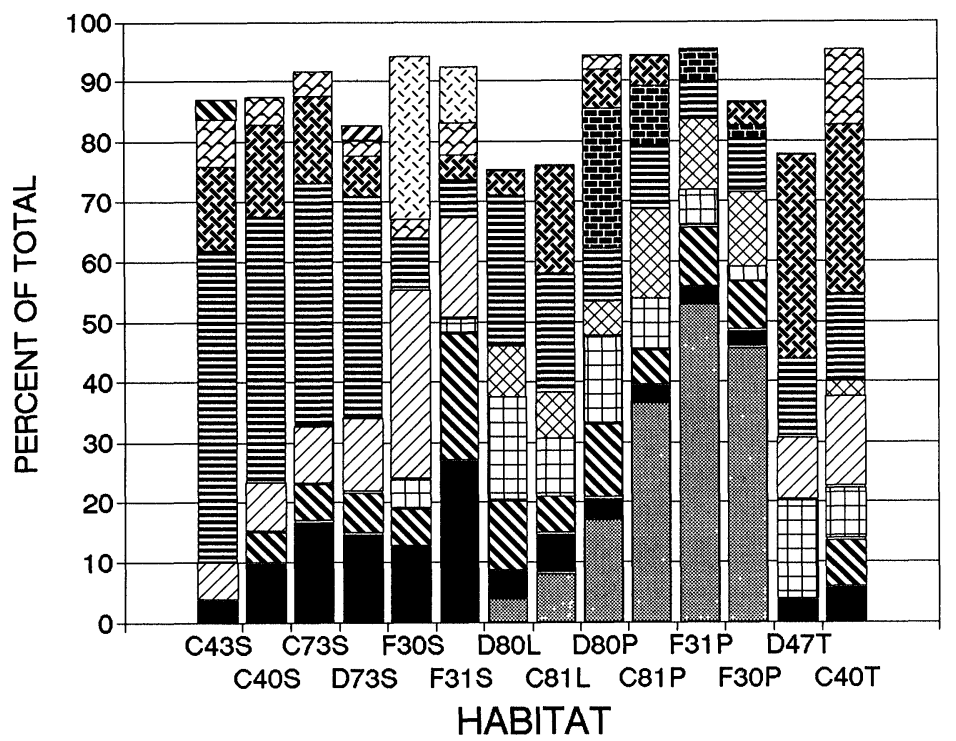

\begin{tabular}{|c|c|c|}
\hline SALTICIDAE & שIIA PISAURIDAE & GNAPHOSIDAE \\
\hline $\mathbb{Z} \mathrm{L}$ & THERIDIIDAE & ERIGONINAE \\
\hline$E$ & AGELENIDAE & NHOMISIDAE \\
\hline
\end{tabular}

Figure 3. Percent representation of twelve of the most abundant families in each habitat. Percentages of less than 2.0 were not included. Habitats arrayed by eye. FCWMA samples. 
At the generic and species level, however, these habitats were not as similar as they might have appeared to be at the family level (Fig. 3). A phenogram (UPGMA), based on the modified Morisita similarity coefficient (Horn, 1966), provides a quantitative measure of species similarity among habitats (Fig. 4). The three main groups mentioned above are clearly separated in the phenogram. Pine foliage (C40S) and pine understory (C73S) were relatively open environments, spatially close to one another, and had more species in common than any other set of habitats. The two tree trunk habitats (D47T, C40T) were quite different, having less than $25 \%$ of species in common. The relative similarity of old field (F31P) and coniferous pitfall (C81P) assemblages may be a function of the generally uncluttered ground surface (cf. Uetz, 1979). The forest surface habitats (D80P, C81P) did not share many species with the immediately adjacent litter (D80L, C81L), less than $50 \%$ in both cases.

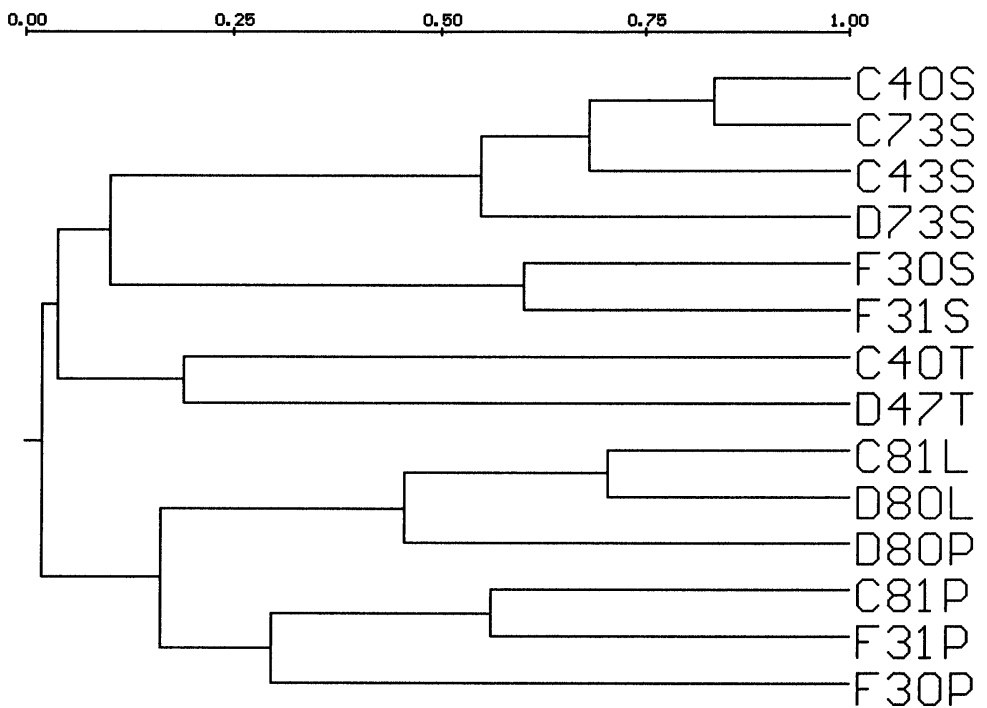

Figure 4. Phenogram (unweighted pair-group method, arithmetic average) based on species using Horn's (1966) modification of Morisita's similarity coefficient, showing the relationships among the FCWMA study area habitats. Cophenetic matrix correlation $=0.9379$. 


\section{Sample comparability}

Different sampling techniques were used depending upon the physical characteristics of each habitat. There is no single, logistically feasible sampling technique that can be used for the array of habitats sampled. For the purposes of calculating J(ESR), there is no formal basis for quantifying the comparability of sample data between different types of habitats. Despite this, some generalizations may be helpful in making such judgments, to the end that future studies might be improved.

Statistical data for the FCWMA habitats are provided in Table 2. The data are arrayed in decreasing order of number of individuals collected. The series of ratios provided in the table were collected to examine how the difference in the number of individuals collected may have influenced other parameters.

The ratio of unique species to species, (U1/S), shows a general increase associated with a decrease in the number of individuals $\left(r^{2}=0.661\right)$. This trend is also reflected in the increase of unique species found as the number of individuals decreases, (U1/I) $\left(\mathrm{r}^{2}=\right.$ 0.611 ). The number of unique species found in collections of spiders both here and in Costa Rica (Edwards, unpubl.) typically varies from 30 to 50 percent of the total.

The number of species unique to specific habitats are listed in Table 2, column U2. These averaged 5.1 species/habitat, with the deciduous pitfall samples having none and the white oak trunks only 1 . This suggests that these habitats offered little to specialists. In the case of the white oak trunk, the single unique species, Drapetisca alteranda Chamberlin, was a specialist and has been taken only on other smooth barked trees outside of the study area, for example beech. Coniferous litter and grass field pitfall trap samples had the largest number of unique species, 14 and 9 respectively.

Unique species that occurred in only one of the 509 quadrats, column U3 in Table 2, averaged 2.9 per habitat. Old field pitfall traps declined most relative to the number unique to that habitat, from 6 to 2. Four of these species had occurred in more than one quadrat, 2 in only one. Those unique to the deciduous understory habitat, 3, continued to be unique overall since each occurred in only one quadrat. These numbers do provide some insight into the specificity of the different habitats. However, given the proclivity 


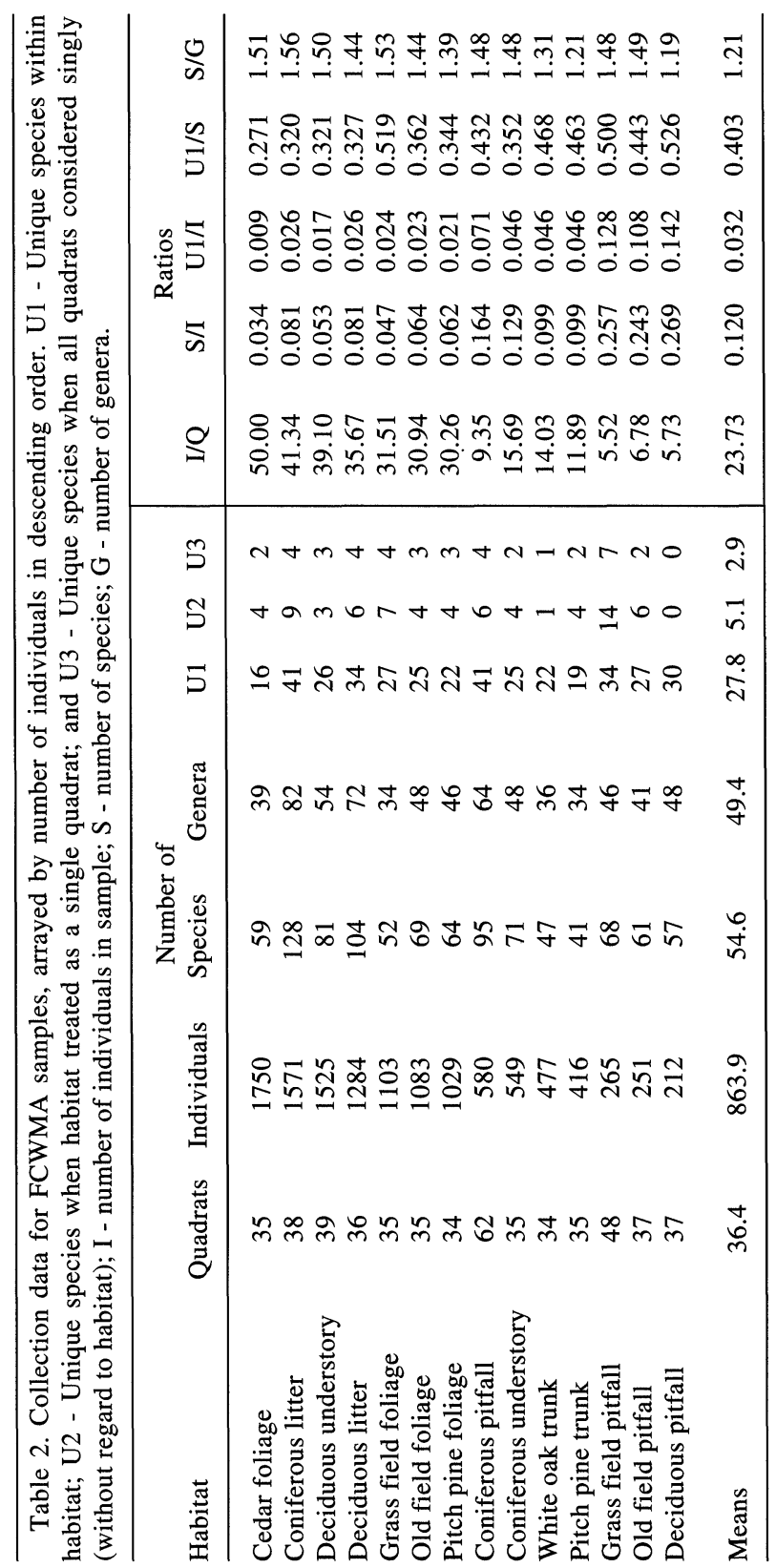


of spiders to wander and mechanisms that distribute some species at random, e.g., ballooning, it is probable that most species will sooner or later be collected in almost any particular habitat. One approach to investigating the selective property of a sampling method might be to examine the behavior of species that show up as unique species in larger collections.

The ratio of individuals/quadrats decreases as the number of individuals decreases. This ratio provides an estimate of the relative abundance of spiders in habitats sampled in the same manner. For future studies where a minimum number of individuals is desired, such data may be used to determine the number of quadrats required, depending on the sampling method used. For example, the smaller number of individuals/quadrat, (I/Q), suggests at a minimum that the number of pitfall and tree trunk quadrats should have been greater in number.

Once the total number of individuals falls below 1,000, the ratios of species/individuals, (S/I), unique species/individuals, (U1/S), and the mean number of individuals/quadrat, (I/Q), tend to vary more. The pitfall sample ratios $S / I$ and U1/I, noticeably depart in value from the rest, being larger in all cases. All ratios for both tree trunk habitats are similar, one to the other, and suggest that tree trunk habitats share unique qualities despite the fact that they share few species.

Of particular interest is the ratio of species to genera, $(\mathrm{S} / \mathrm{G})$. Only two habitats had S/G ratios considerably less than 1.4 , pitch pine trunk and white oak trunk (Table 2). In terms of potential niches, these two habitats were less complex than all others.

Jennings et al. (1988) collected 76 genera and 125 species in pitfall traps in spruce-fir forests of Maine, $(\mathrm{S} / \mathrm{G}=1.64)$. Young et al. (1989) collected 22 genera and 29 species in Spanish moss in Mississippi ( $\mathrm{S} / \mathrm{G}=1.32)$. Jennings (1976, Tab. 1, p. 112) summarized the results of 16 faunal studies of spiders from North American trees. The ratio in these studies varied from 1.00 to 2.03 , mean $=1.37$. Deciduous floor pitfall traps in a mature second growth forest in Delaware had a ratio of 1.54 , and a somewhat xerophytic mixed oak forest in Illinois had a ratio of 1.61 (Uetz, 1979). The similarity of these species/genus ratios with those obtained from FCWMA samples (Table 2) provides some assurance that the samples collected were comparable to those reported in other studies. 
Table 3. Comparison of spider species to genera, ratios by area. Kaston (1981) data from revised table of statistics, p. 963.

\begin{tabular}{cclc}
\hline Species & Genera & Area & Ratio: Species/Genera \\
\hline 304 & 147 & FCWMA (all data this study) & 2.07 \\
390 & 166 & FCWMA (entire study area) & 2.35 \\
465 & 188 & Southwest Cape Cod & 2.47 \\
478 & 218 & Connecticut (Kaston) & 2.19 \\
611 & 242 & Region (Kaston) & 2.52 \\
683 & 241 & All New England (Kaston) & 2.83 \\
\hline
\end{tabular}

Comparisons of the species/genus ratio for other areas in New England are shown in Table 3. As the area covered increases, and consequently the number of habitats, the species/genus ratio increases. The S/G ratio might well serve as a useful 'generic diversity index' when comparing similar habitats. It has the disadvantage of the relative subjectivity of the concept of a genus and thus is especially troublesome to calculate when comparing data prepared at different times and by different people. Whatever evolutionary mechanism underlies the similarity in these ratios, a

Table 4. Comparison of species richness estimates, J(ESR), for FCWMA habitats. Number of species in descending order. Note that J(ESR) shows little relation to number of individuals in sample (cf. Table 2).

\begin{tabular}{lcccc}
\hline Habitat & $\begin{array}{c}\text { Observed } \\
\text { number of } \\
\text { species }\end{array}$ & J(ESR) & Variance & $\begin{array}{c}\text { Confidence } \\
\text { interval }\end{array}$ \\
\hline Coniferous litter & 128 & 167.9 & 65.0 & 16.4 \\
Deciduous litter & 104 & 136.1 & 37.7 & 13.5 \\
Coniferous pitfall & 95 & 135.3 & 47.1 & 13.7 \\
Deciduous understory & 81 & 104.4 & 59.7 & 17.0 \\
Coniferous understory & 71 & 94.3 & 26.8 & 10.5 \\
Old field foliage & 69 & 93.3 & 28.3 & 10.8 \\
Grass field pitfall & 68 & 101.3 & 55.1 & 12.3 \\
Pitch pine foliage & 64 & 85.4 & 25.0 & 10.2 \\
Old field pitfall & 61 & 87.3 & 30.5 & 12.2 \\
Cedar foliage & 59 & 74.5 & 10.4 & 6.5 \\
Deciduous pitfall & 57 & 82.2 & 26.1 & 11.2 \\
Grass field foliage & 52 & 78.2 & 23.5 & 9.8 \\
White oak trunk & 47 & 68.4 & 23.1 & 9.8 \\
Pitch pine trunk & 41 & 59.5 & 18.2 & 8.7 \\
\hline
\end{tabular}




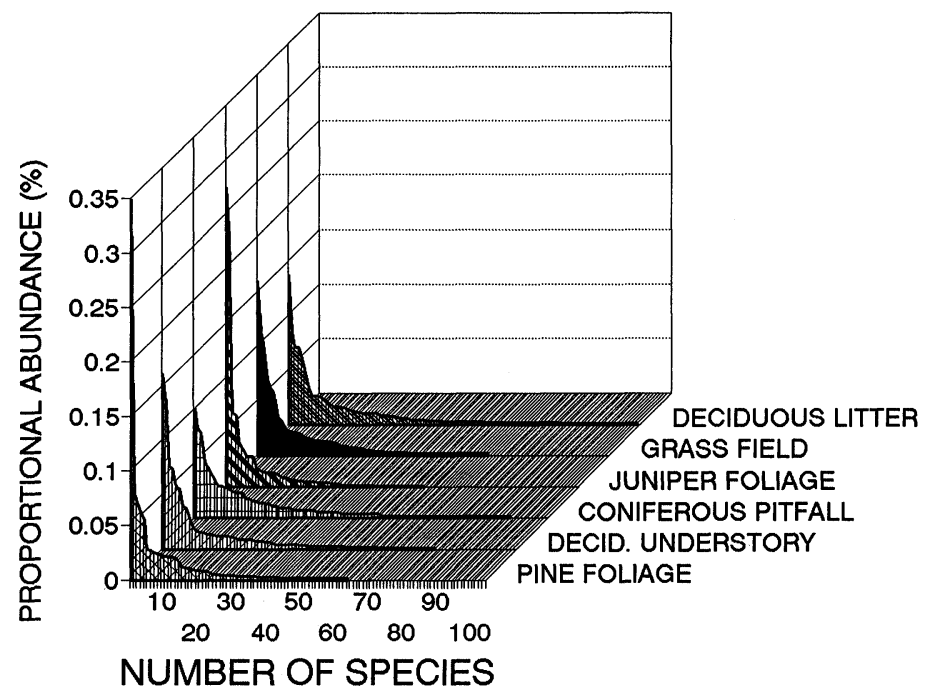

Figure 5. Proportional abundance of spider species in representative FCWMA habitats. Note that these distributions are not characterized by a few species at the higher end, but many 'rarer' species. The distributions for those habitats not included are similar to those presented.

significant departure from these values might suggest that the habitats being investigated differed in their ecological 'breadth'.

\section{Community Structure}

The J(ESR) estimates for the individual FCWMA habitats are given in Table 4. These values show no obvious relationship to other habitat parameters provided in Table 2, e.g., number of individuals and species.

All habitats were characterized by relatively large numbers of rare species. With the exception of juniper (C43S) and pine foliage (C40S) habitats, the remaining 12 habitats were not dominated by one or two species and were similar to those figured. Six representative examples of species proportional abundance (skew) are shown in Fig. 5.

I had anticipated that the distributions of species numbers by quadrat would resemble the logarithmic or lognormal; however, this was not the case. Geometric plots (log base 2 scale) of the distributions varied from what appear to be logarithmic, to lognormal, 

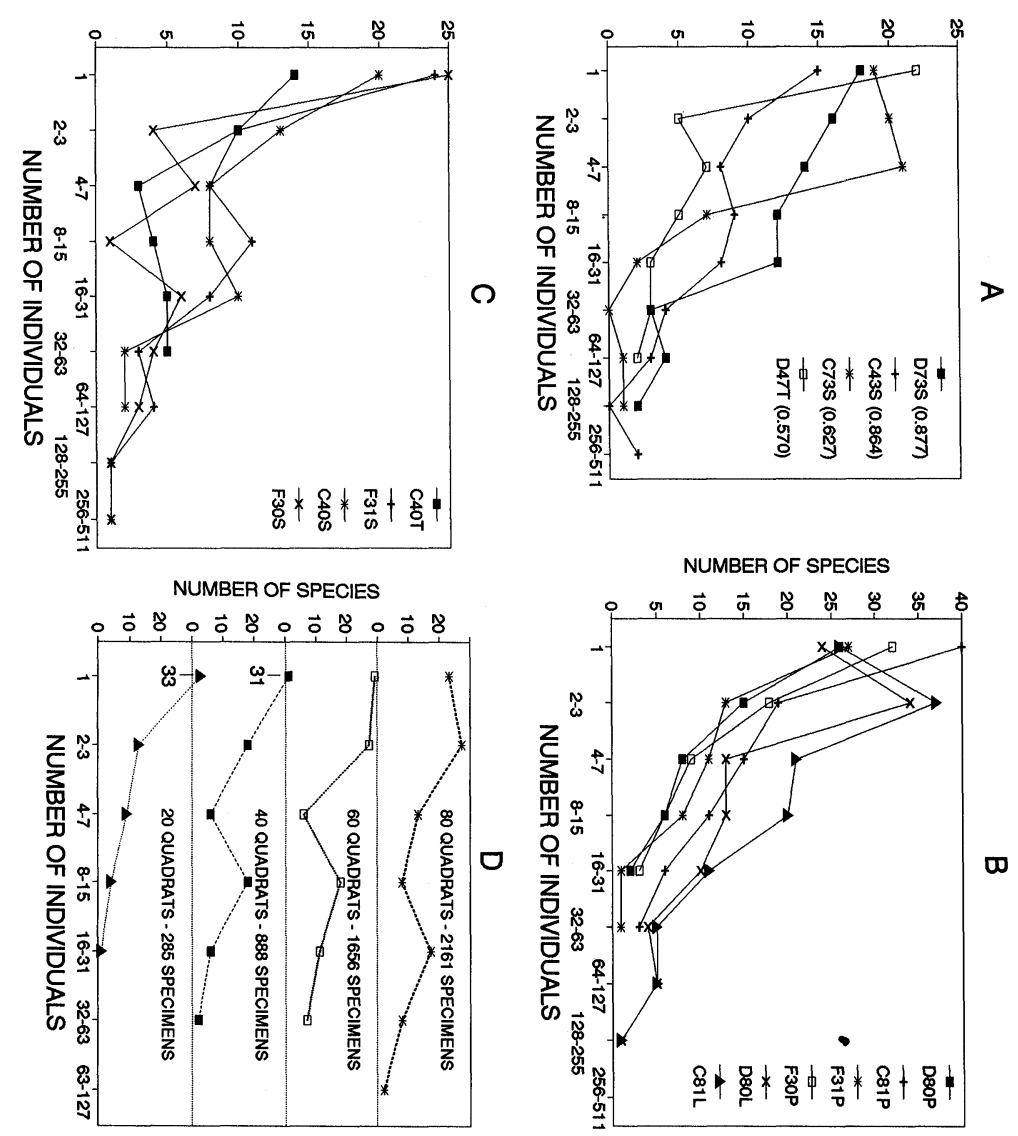
to bimodal. Only four of the 14 habitat samples (using the Chisquare goodness of fit test) survived the null hypothesis that the distributions were lognormal (Figure 6A). Fig. 6A shows that the Chi square test (test results in parentheses on graph following habitat code) is of relatively low power. Some similarities may be seen in the distributions by habitat and sampling method. In figure 6B the litter samples for the deciduous and coniferous woods (D80L, C81L) have a clear mode in the second octave, whereas the pitfall samples were dominated by unique species (first octave). Pitfall traps appear to be the most eclectic sampling technique and tend to capture, in small numbers, a wide variety of errant wanderers (cf. Uetz et al., 1976). The samples obtained by sweeping (Fig. 6C) in fields (F30S, F31S), by beating pitch pine foliage (C40S), and by bark removal from pitch pine trunks (C40T) have the greatest number of species in the first octave, and show a tendency to bimodality.

The 80 quadrats of the mixed deciduous-coniferous litter (M82L) from East Falmouth show a progression from a logarithmic distribution (20 quadrats) to one that was clearly bimodal ( 80 quadrats) (Fig. 6D). Individuals of many species in the lower mode were those that overwinter in the litter, but during warmer months are found above ground, e.g., orb weavers, philodromids, some therids and salticids. Some of these distributions resemble those of Figs. 6A, 6B, and 6C.

In addition to the fact that many spider species are uncommon, the vagility (sensu lato) of spiders accounts for some of the variability observed. The propensity to move about is well illustrated by the large number of non-resident species to be found on rural delivery mailboxes (Edwards et al., 1991). In FCWMA, some uncommon species were strongly aggregated and consequently restricted to relatively small sectors of apparently homogeneous

Figure 6. Number of individuals representing each species, plotted using a geometric scale (in $\log$ base 2 octaves). A. These four are the only habitats that meet the null hypothesis as lognormal distributions (i.e., significance level $>0.5$ ). Chisquare goodness of fit significance level in parenthesis following habitat code. FCWMA samples. B. FCWMA habitat distributions approximating logarithmic distributions. C. FCWMA habitat distributions with large numbers of unique species and showing a tendency toward bimodality. D. Changes in the distributions of East Falmouth (M82L) samples, as the number of quadrats increased. Note the progression from a hollow curve to a bimodal distribution. See text for details. 
habitats. Such aggregations tended to show up as rare species. Other factors that contribute to variability in distributions include temporal isolation and shifts in habitat associated with growth of the spider.

\section{Estimates of species richness for FCWMA study area}

When several smaller habitats and ecotones in FCWMA not sampled in this study are included, a total of 390 species have been collected over a period of six years. This number can be considered the lower bound for the number of species in the area. Certainly more will turn up. The jackknife estimate of species richness for all FCWMA habitats investigated in this study, based on a total of 509 quadrats, 304 species and 41 unique species is 344.9 species (Table 5).

When all quadrats were used to calculate the species richness estimate as in above example, many species that were unique to specific habitats were not calculated as unique (U3 in Table 2) since they occurred in more than one quadrat within that habitat. If each habitat collection is pooled as a single quadrat a very different estimate results. For these 14 pooled quadrats, with 72 unique species, the $\mathrm{J}(\mathrm{ESR})$ is 373.6 species (Table 5). The increase in unique species came about because 31 species were unique to specific habitats.

Five separate sets of 210 and 350 quadrats were selected at random, made up, respectively, of 15 and 25 quadrats from each of the 14 habitats. The average values for these sets are given in Table 5. On both the individual and pooled (by habitat) quadrat basis, the estimates increase at a decreasing rate as sample size increases. The upper limit of the confidence interval does not reach the observed number of species (390) for any of the individual quadrat sets. However, for the most inclusive of the 14 quadrats pooled by habitat, the upper limit is 401.8 .

\section{SUMMARY}

The final estimate of 373.6 species based on pooled quadrats for each habitat was, intuitively, satisfactory. The relatively large number of rare species and the possibility of not recognizing unique species among the immature individuals suggests that an underestimate might be expected, as well as a decrease in the 


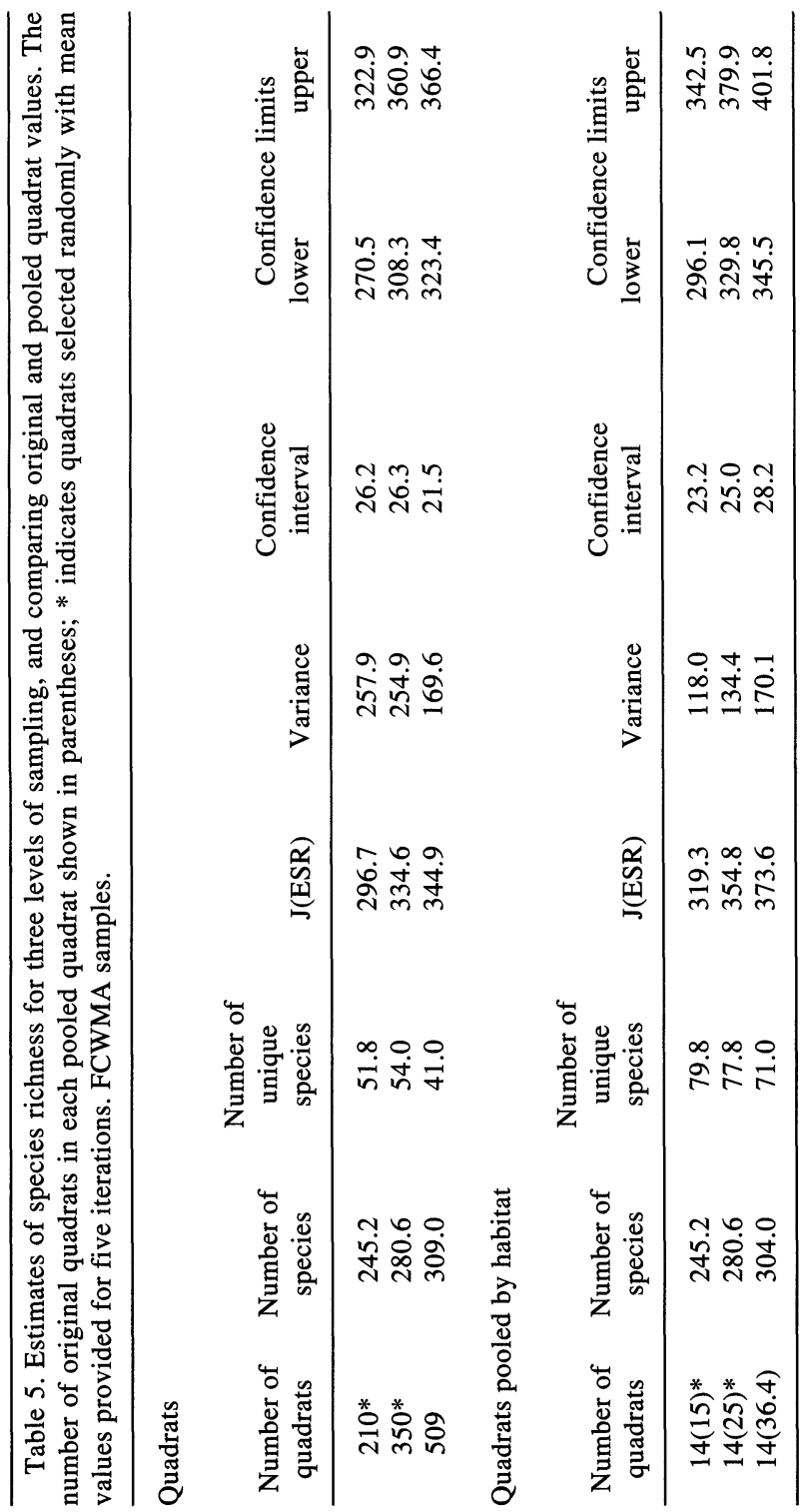


coverage of the confidence interval. Since all the habitats shared similar distributions of species proportions, one potential source of bias was reduced. On the other hand the obvious differences in number of species found in each habitat (cf. Table 2) would be expected to introduce errors that cannot as yet be defined. The data in Table 5 did suggest that, with a few more samples, an asymptote might be reached, at a level consistent with the results of extensive collecting over many years.

Nonetheless, many questions need to be resolved. Further simulations that consider the manner in which spiders are distributed, their numbers, and their propensity for wandering would be helpful.

The question of bias introduced by the selectivity of different sampling methods needs further investigation. There is no single, logistically feasible, universal sampling technique for the variety of habitats sampled nor is there any likelihood that there will be in the near future. To some degree the differences noted in various aspects of samples from different habitats were related to numbers of quadrats taken and in turn individuals (Table 2), and not in any obvious way to the sampling method. The principal effect of gear selectivity would appear to be missing certain species, resulting in an exaggeration in the estimate of the number of species considered uncommon or unique. The use of the burlap strip on oak trunks, in an effort to also sample those species that occupied deep hollows in the trunk, was clearly selective and a failure. Brushing took all species observed in recesses but one.

A more significant aspect of selectivity would be temporal. Some species are totally unavailable seasonally. Had sampling in FCWMA been done in the month of May, a substantial increase in the number of spider species would have occurred.

The increased variability seen in the ratios discussed earlier when the number of individuals fell below 1000 does suggest that at least a certain number of individuals be collected from each habitat. With the exception of pitfall traps, one can estimate the area and/or volume sampled and adjust the number of quadrats accordingly. Such estimates, however, would be crude at best. A better initial approach might be that of determining the number of quadrats to be taken in inverse proportion to the average number of individuals taken in each habitat (column I/Q in Table 2). Thus, for 
example, for every cedar foliage sample $(\mathrm{I} / \mathrm{Q}=50.0)$, approximately 10 pitfall samples would be used in grass fields $(\mathrm{I} / \mathrm{Q}=$ 5.52).

Coddington et al. (1991) recently reported on spider faunas in several tropical locales, and on some of the problems encountered both in sampling and analyzing species diversity data. They emphasize that sampling procedures should be fast, simple, and inexpensive. The study reported here was carried out almost entirely by the author. Collecting the 509 samples took approximately 280 hours. Sorting litter samples, identifying specimens, recording data, and analyzing data, required an additional 400 hours. Fortunately, prior to this study, I had developed a reference collection of most of the species encountered. This collection included adults and some immatures. Dealing with immatures required considerable effort and was the most time consuming aspect of this study. A well trained assistant would have reduced the time required, both in the field and in the laboratory, perhaps by half.

It should be noted that material collected for the purposes of estimating species richness, based on quadrat sampling, also provides data useful for other types of studies.

\section{ACKNOWLEDGMENTS}

I thank James. F. Heltshe for his advice and council about the jackknife estimator. Jonathan Coddington critiqued an earlier manuscript draft and made many helpful suggestions. James. H. Redner assisted with the determination of erigonine and Meioneta species. Eric Edwards assisted in various aspects of this study. The comments and suggestions of reviewers were gratefully received. A grant from the Massachusetts Natural Heritage \& Endangered Species Program helped in part to defray expenses.

\section{Literature Cited}

Coddington, J. A., C. E. Griswold, D. S. Davila, E. Penaranda, and

S. F. LARCHER

1991. Designing and testing sampling protocols to estimate biodiversity in tropical ecosystems. Pp. 44-60. in Dudley, E. C. (Ed.), The Unity of Evolutionary Biology: Proc. Fourth Inter. Cong. of Systematic and Evolutionary Biology. Dioscorides Press, Portland, OR. 
EDWARDS, R. L.

1993. New records of spiders (Araneae) from Cape Cod, Massachusetts, including two possible European immigrants. Ent. News 104(2): 79-82.

EDWARDS, R. L. AND E. H. EDWARDS

1991. Spiders (Araneae) associated with rural delivery mailboxes, Mashpee, Massachusetts. Ent. News 102(3): 137-149.

Fisher, R. A., A. S. Corbett, AND C. B. Williams

1943. The relation between the number of species and the number of individuals in a random sample of an animal population. J. Anim. Ecol. 12: $42-58$.

HELTSHE, J. F. AND N. E. FORRESTER

1983. Estimating species richness using the jackknife procedure. Biometrics 39: $1-11$.

HORN, H. S.

1966. Measurement of "overlap" in comparative ecological studies. Amer. Nat. 100: 419-424.

Houseweart, M. W., D. T. Jennings, and J. C. Rea

1979. Large capacity pitfall trap. Ent. News 90: 51-54.

JENNINGS, D. T.

1976. Spiders on Black Walnut. Amer. Mid. Nat. 95(1): 111-119.

Jennings, D. T. AND J. A. Collins

1987. Coniferous-habitat associations of spiders (Araneae) on red spruce foliage. J. Arachnol. 14: 315-326.

Jennings, D. T., M. W. Houseweart, C. D. Dondale, And J. H. Redner

1988. Spiders (Araneae) associated with strip-clearcut and dense spruce-fir forest of Maine. J. Arachnol. 16: 55-70.

KASTON, B. J.

1981. Spiders of Connecticut. State Geol. and Nat. Hist. Survey Bull. 70: $1-1020$, revised ed.

KEMPTON, R. A.

1979. The structure of species abundance and measurements of diversity. Biometrics 35: 307-321.

SMith, W. AND J. F. Grassle

1977. Sampling properties of a family of diversity measures. Biometrics 33: 283-292.

UETZ, G. W.

1979. The influence of variation in litter habitats on spider communities. Oecologia (Berl.) 40: 29-42.

UETZ, G. W. AND J. D. UNZICKER

1976. Pitfall trapping in ecological studies of wandering spiders. J. Arachnol. 3: $101-111$.

Young, O. P. AND T. C. LOCKLEY

1989. Spiders of Spanish Moss in the delta of Mississippi. J. Arachnol. 17: 143-148. 

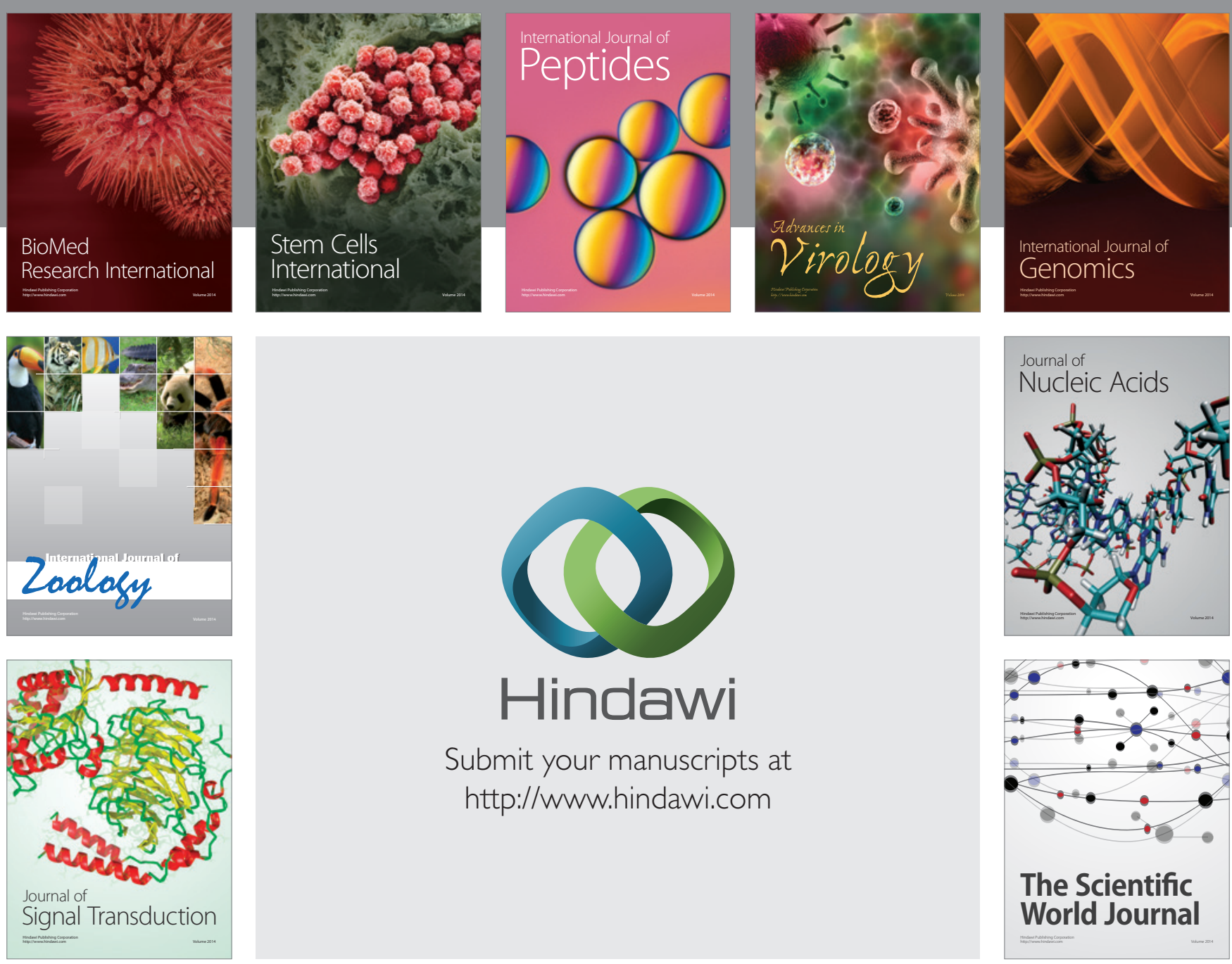

Submit your manuscripts at

http://www.hindawi.com
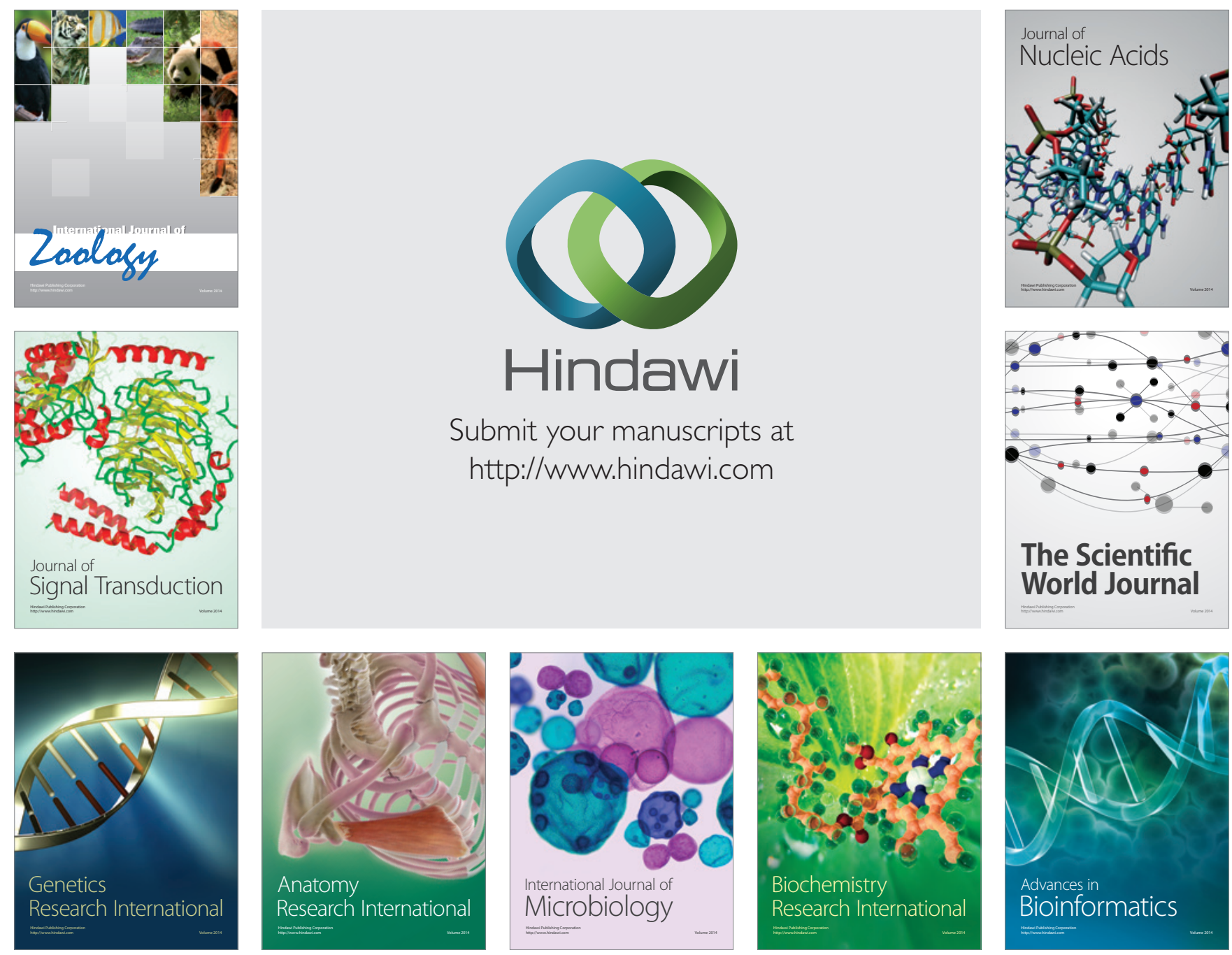

The Scientific World Journal
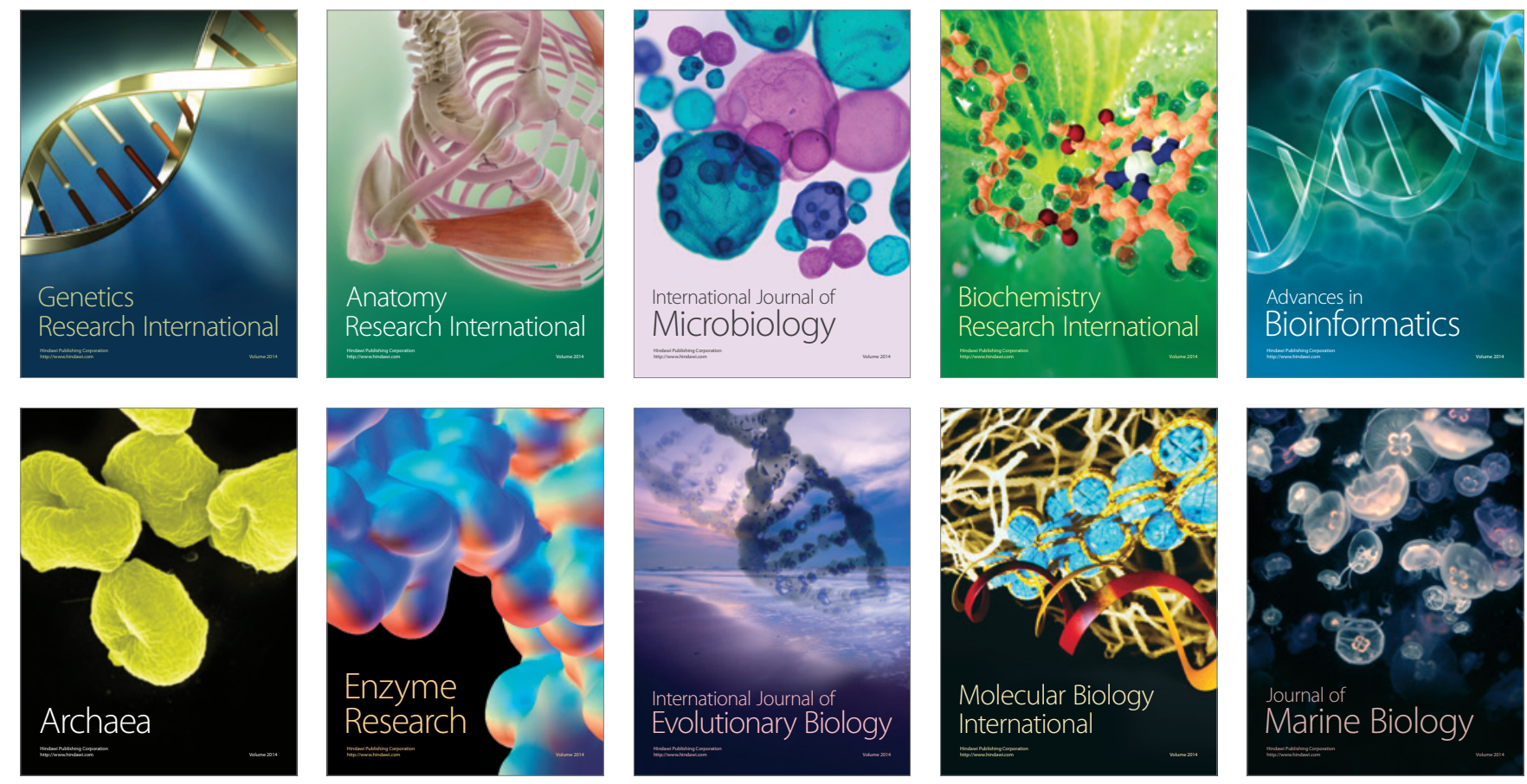